\title{
ESTUDO DO DESEMPENHO DE CATALISADORES DESTINADOS À PRODUÇÃO DE HIDROGÊNIO A PARTIR DA REFORMA A VAPOR DE METANOL E DIMETIL ÉTER
}

\author{
J. L. C. W. Pimenta ${ }^{1}$, H. O. Correia ${ }^{1}$, R. Menechini Neto, O. A. A. Santos ${ }^{1}$ e L. M. M. Jorge ${ }^{1}$ \\ ${ }^{1}$ Universidade Estadual de Maringá, Departamento de Engenharia Química \\ E-mail para contato: 1mmj@deq.uem.br
}

\begin{abstract}
RESUMO - A partir do empacotamento de um micro-reator com catalisadores industrial HiFUEL R120 e sol-gel, a base de cobre, foram executados diversos ensaios reacionais com metanol e dimetil éter em diversas temperaturas, vazões e razões molares de alimentação, [Água]/[Combustível], medindo-se a temperatura no leito e a composição da corrente efluente, a fim de identificar a viabilidade destes catalisadores para a reforma a vapor dos compostos citados, o que proporcionaria o desenvolvimento e utilização de um reator de reforma de multiprocessamento capaz de fornecer hidrogênio com baixo teor de monóxido de carbono para uma célula à combustível do tipo PEM. Os resultados revelam que o catalisador sol-gel apresentou melhor desempenho que o catalisador comercial HiFUEL R120 para a reforma a vapor do metanol.
\end{abstract}

Palavras chave: Metanol, reforma a vapor, dimetil éter, hidrogênio.

\section{INTRODUÇÃO (FONTE 14)}

O hidrogênio tem sido o foco de inúmeras pesquisas, mostrando-se como uma fonte ou intermediário alternativo e flexível para a produção de eletricidade limpa. O gás já é amplamente utilizado na indústria química, já para a produção de eletricidade, é usado preferencialmente em células a combustível, que possuem alta eficiência e vem em diversos modelos que operam nas mais variadas condições.

O metanol é um candidato muito promissor para fonte de hidrogênio na alimentação de células a combustível, já que apresenta grande quantia de hidrogênio na molécula e pode sofrer reforma catalítica para produzir correntes ricas no gás em questão, com baixos níveis de contaminantes como $\mathrm{CO}$ e $\mathrm{CO} 2$. A vantagem no uso de metanol como fonte de hidrogênio vem do fato de que, ao contrário do gás, o álcool é facilmente armazenado, sem ser necessário o uso de grandes cilindros que armazenam gás a altas pressões. (TESSER et al, 2009). O metanol pode ser gerado a partir do gás de síntese, que pode ser obtido da biomassa no geral, do carvão mineral, gás natural e também de derivados de petróleo. Nesse contexto, o Brasil tem como vantagem a grande variedade de fontes de biomassa disponíveis para produção de gás de síntese e metanol a partir de fontes renováveis, podendo até se tornar autossuficiente na produção de metanol.

O foco desse estudo será em um reator de reforma a vapor de metanol para a produção de hidrogênio limpo, desprovido de quantias significativas de contaminantes como o monóxido de carbono, que é prejudicial ao funcionamento de células a combustível. Além 
disso, é interessante a construção de um reator de reforma a vapor de multicombustível, que seja capaz de fornecer uma corrente limpa de hidrogênio que pode vir a ser utilizado nos mais diversos processos, entre eles a alimentação de uma célula a combustível, algo já provado em trabalhos anteriores (BADMAEV e SNYTNIKOV, 2008). Há trabalhos que mostram que um mesmo catalisador poderia ser usado para a reforma de dois combustíveis, no caso o metanol e o dimetil éter (TAKEISHI e SUZUKI,2004, FAUNGNAWAKIJ e EGUCHI, 2011). Trabalhos anteriores apontam que o uso de um catalisador a base de cobre permitiria o uso dos dois combustíveis previamente citados, sem a necessidade de grandes modificações no sistema do reator. Sendo assim foram sintetizados catalisadores a base de cobre pela rota solgel, que são candidatos a serem utilizados em reatores de reforma a vapor (LENZI, G. G., 2008) e aqui serão aplicados ao multiprocessamento.

O objetivo desse estudo fica então na construção de um reator para a reforma a vapor de metanol, onde serão empregados dois catalisadores a base de cobre: o comercial HiFuel R120 e um catalisador previamente preparado em laboratório pela rota sol-gel. Irá testar-se a atividade catalítica de ambos os catalisadores em diversas condições para avaliar-se qual seria a melhor, tendo como objetivo uma alta conversão e baixa concentração de contaminantes na corrente de saída. Também fica como objetivo a análise da viabilidade de um reator multicombustível para a produção de hidrogênio a partir de metanol ou dimetil éter, utilizando um mesmo catalisador.

\section{MATERIAIS E MÉTODOS}

O reator construído para a reforma de metanol (Figura 1) consistirá de três partes: uma proveta contendo a solução de reagentes para a reforma, juntamente com cilindros de gases (hidrogênio e nitrogênio) utilizados durante o aquecimento e resfriamento, bem como na ativação do leito catalítico; o reator contendo o leito catalítico onde ocorre a reação; e um separador de fases ligado a um cromatógrafo de gases para a análise da composição da corrente gasosa de saída. Na proveta ficará armazenada a solução de metanol/água, para reforma a vapor de metanol, e somente água, na reforma a vapor de éter metílico. A solução é conduzida ao pré-aquecedor por meio de uma bomba peristáltica. Na entrada do préaquecedor a corrente de líquidos (metanol/agua e água deionizada) é misturada a uma corrente de gases (nitrogênio, hidrogênio, éter metílico) provenientes de cilindros de gases.

Os reagentes são previamente aquecidos até a uma temperatura de $200{ }^{\circ} \mathrm{C}$ no préaquecedor e nessa condição os reagentes seguirão para o reator de leito fixo alocado no interior de um forno elétrico. Na saída do reator os produtos de reação são conduzidos a um condensador e um separador de fases a fim de remover os compostos condensáveis. Da saída do separador de fases saem uma corrente gasosa e uma corrente líquida, cujas composições serão quantificadas por cromatografia gasosa. 

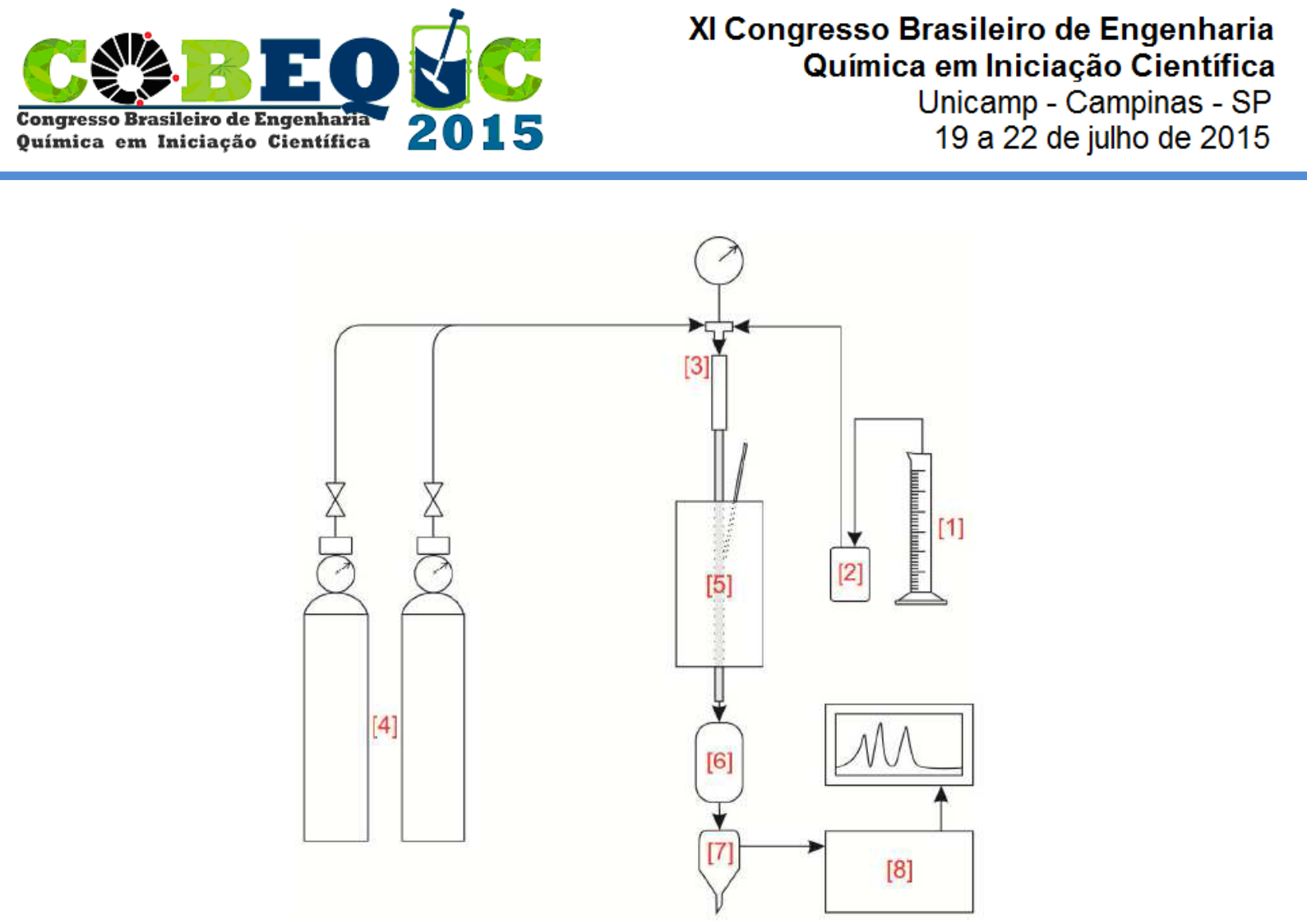

Figura 1 - Proposta do Módulo Experimental.

Notação: [1] proveta, [2] bomba peristáltica, [3] pré-aquecedor, [4] cilindros de gases,[5] forno elétrico, [6] condensador, [7] separador de fases, [8] cromatógrafo.

Este reator deve ser adaptado para permitir a alimentação de dimetil éter que será alimentado independentemente da água. Após carregar o reator com catalisador e ativá-lo com hidrogênio será efetuado um ensaio de longa duração com metanol ou dimetil éter a fim de avaliar-se o comportamento dos catalisadores no período de desativação inicial, procurandose avaliar a atividade inicial em termos de conversão e a atividade final, quando o catalisador passar a apresentar uma conversão estável.

Logo a seguir do período de desativação inicial, serão efetuados vários ensaios em diversas condições de vazão, temperatura do forno e razão molar de alimentação ([metanol/água] ou [dimetil éter/água]), medindo-se as composições dos produtos líquidos e gasosos, temperatura e vazão da corrente efluente do reator.

\section{RESULTADOS E DISCUSSÕES}

A partir de cromatogramas obtidos ao se analisar a corrente de saída do reator a diversas temperaturas de operação foi concluído que as condições de melhor desempenho, visando conversão e seletividade de $\mathrm{H} 2$ em relação a $\mathrm{CO}$ são de uma temperatura e leito de $300^{\circ} \mathrm{C}$ e razão molar de $\mathrm{CH}_{3} \mathrm{OH}$ e água de 1:3. A quantidade de catalisador no leito foi de aproximadamente $500 \mathrm{mg}$ (massa aferida antes da redução) com granulometria de $0,6 \mathrm{~mm}$ a $0,85 \mathrm{~mm}$ em todos os ensaios.

Nota-se no gráfico a seguir que há uma variação na conversão do metanol ao longo do tempo de operação do reator, sendo que a variação é mais brusca nas primeiras horas de reação e torna-se desprezível - o que indica uma operação estável - após a marca das $25 \mathrm{~h}$. 
Figura 2- Gráfico de conversão de metanol x tempo para catalisador HiFuel R120

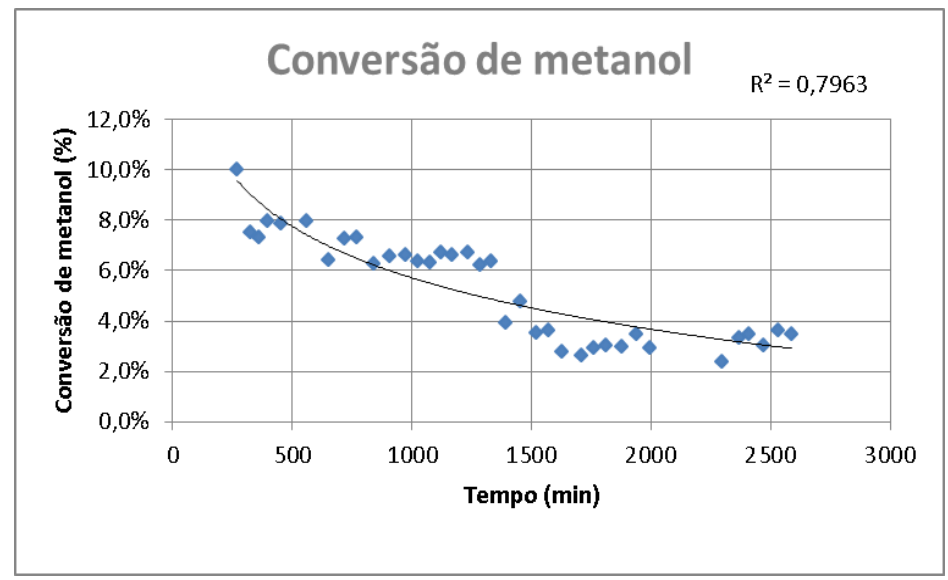

Figura 3- Gráfico de Razão molar H2/CO x tempo para catalisador HiFuel R120

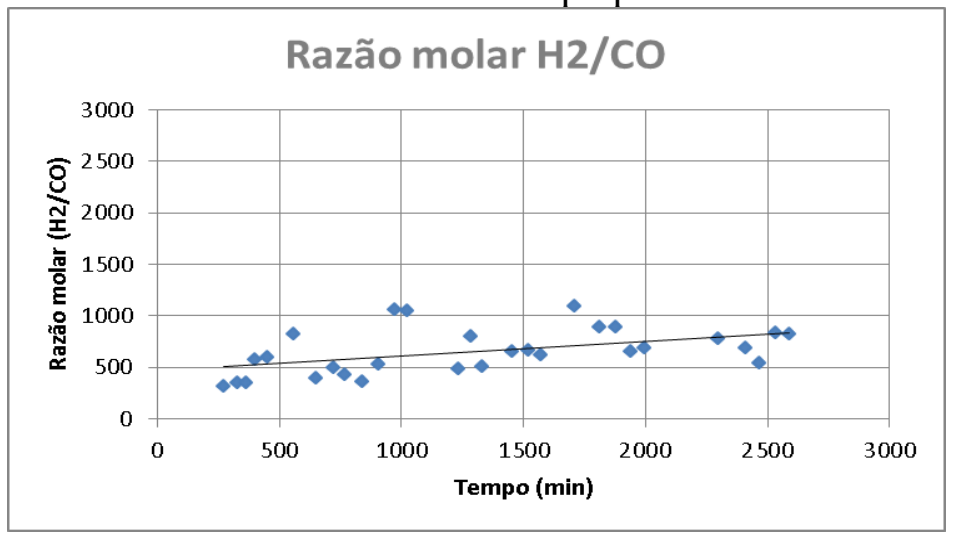

A figura 3 mostra que a seletividade de $\mathrm{H}_{2}$ em relação a $\mathrm{CO}$ permanece alta durante todo o período da reação, sendo que seu valor gira em torno de 750, o que mostra que há uma boa taxa de reação de water-gas-shift. $\mathrm{O}$ gráfico mostra que o catalisador aqui utilizado poderia ser empregado em um reator e usado como fonte de hidrogênio com baixa quantia de contaminantes, no caso especificamente o monóxido de carbono.

O catalisador HiFuel R120 não apresentou atividade catalítica significante ao ser empregado na reforma a vapor do éter dimetílico em nenhuma das tentativas efetuadas nas condições aqui apresentadas.

Devido ao fato anteriormente citado, uma nova meta foi traçada durante a realização da pesquisa: a comparação entre o comportamento do catalisador neste trabalho estudado e um preparado pela rota sol-gel em laboratório. $\mathrm{O}$ catalisador sol-gel foi carregado no leito catalítico e foi utilizado nas mesmas condições previamente descritas para o catalisador comercial.

A partir da figura 4 nota-se que a conversão de metanol sobre o leito catalítico de catalisador sol-gel é maior do que aquela para o HiFuel R120, dadas as mesmas condições. 
Figura 4- Gráfico de conversão de metanol x tempo para catalisador sol-gel

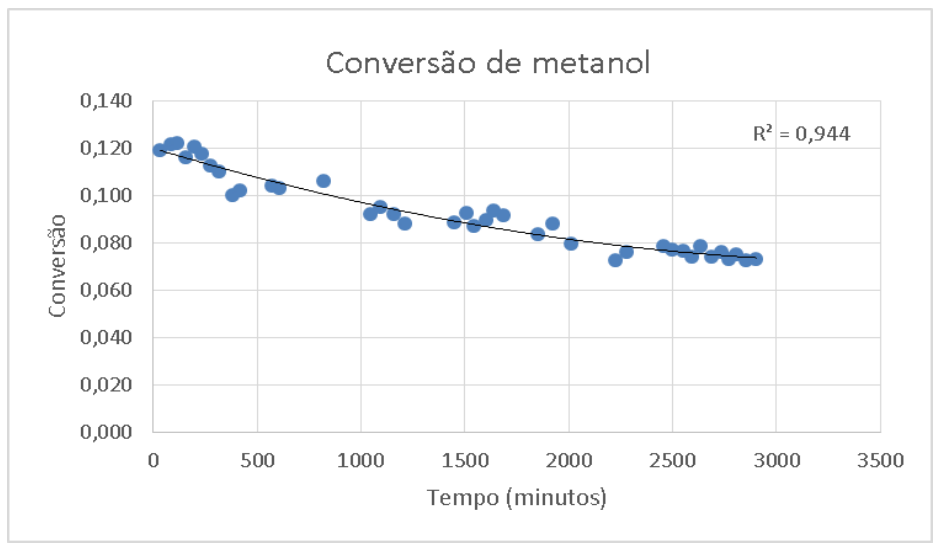

Figura 5- Gráfico de razão molar H2/CO x tempo para catalisador sol-gel

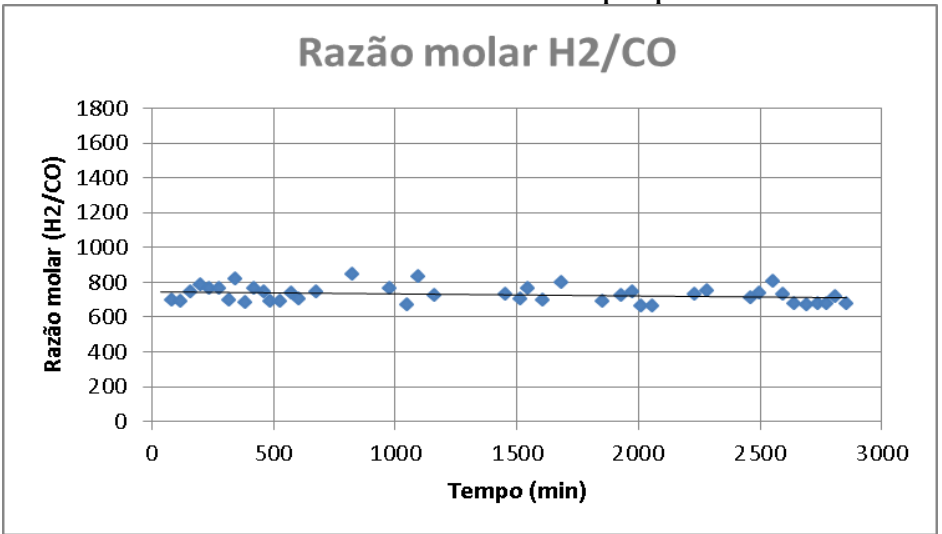

O ensaio também sugere que o catalisador preparado em laboratório apresenta uma estabilidade superior àquela do catalisador comercial nas condições aplicadas. Também foi possível perceber que a seletividade de $\mathrm{H}_{2}$ sobre $\mathrm{CO}$ foi mais alta e mais estável do que no ensaio anteriormente citado (Figura 5), mostrando que o catalisador sol-gel gera uma corrente mais limpa de hidrogênio (em relação a monóxido de carbono) nas condições estudadas.

Figura 6- Comparação da conversão entre catalisadores

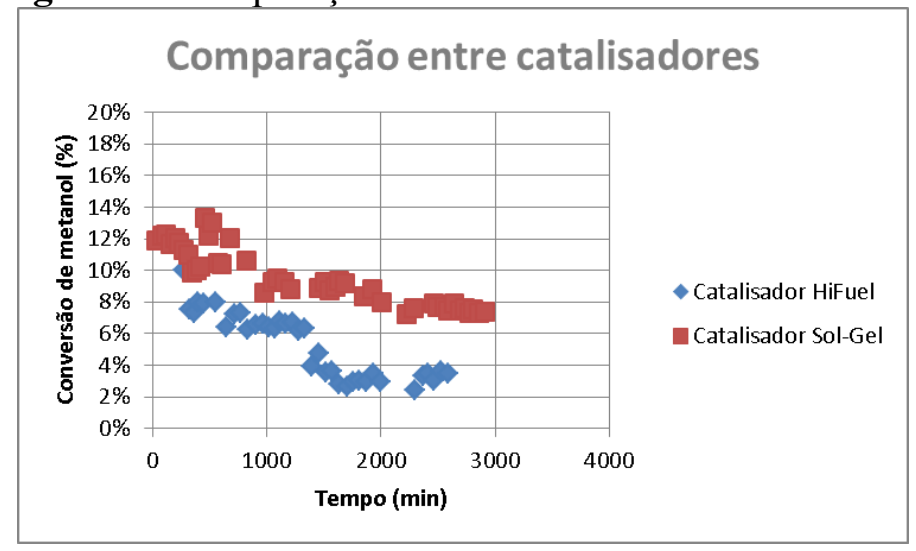


A figura 6 mostra que o catalisador sol-gel apresentou um desempenho superior em termos de conversão e estabilidade durante o período de operação e condições aplicadas em relação ao catalisador comercial HiFuel R120.

\section{CONCLUSÕES}

O catalisador HiFuel R120 apresenta boa atividade catalítica na reforma a vapor de metanol às condições de operação citadas no trabalho: temperatura de leito de $300^{\circ} \mathrm{C}$, pressão ambiente de 0,95atm e razão molar de reagentes metanol:água de 1:3. O catalisador sol-gel apresentou propriedades melhores em relação ao comercial, apresentando maior razão molar de hidrogênio gasoso em relação a monóxido de carbono, assim como apresentou uma maior conversão de produtos em reagentes desde o começo da reação. Sendo assim, é interessante o uso do catalisador apresentado nesse trabalho para reforma a vapor de metanol produzindo correntes de baixos níveis de contaminantes (monóxido de carbono), indicando que seu uso em reatores para a produção de hidrogênio e até para a alimentação de uma célula de combustível do tipo proton exchange membrane (PEM), sendo necessário pouco tratamento da corrente-produto para uso direto na célula. Além disso, o catalisador preparado em laboratório também teve uma estabilidade maior, apresentando um menor decaimento na atividade catalítica durante as $48 \mathrm{~h}$ de reação, algo que demonstra que um reator de escala industrial contendo tal catalisador necessitaria de um tempo menor para atingir regime permanente de operação e consequentemente operaria de maneira mais eficiente desde o começo da reação.

Uma pesquisa mais aprofundada sobre o desempenho do catalisador sol-gel frente a reação de reforma a vapor do dimetil éter apresentou-se como uma continuação interessante para este trabalho, visando a possibilidade no uso de tal catalisador num reator de multiprocessamento de álcool e/ou éter metílicos.

\section{REFERENCIAS}

[1] ARMOR, J. N., 1999, "The multiple roles for catalysis in the production of H 2", Applied Catalysis A: General, v.176, p.159-176.

[2] FAUNGNAWAKIJ, K., EGUCHI, K., 2011, "Dimethyl Ether - Reforming Catalysts for Hydrogen Production", Catal Surv Asia, v.15, p.12-24.

[3] LENZI, G. G., 2008, “Avaliação dos catalisadores de níquel sol-gel e industrial e modelagem do reator para a reação de reforma a vapor de metano", Tese Doutorado, UEM, Paraná, Brasil.

[4] MENECHINI NETO, R., "Contribuição ao projeto de um reator de reforma a vapor de metanol de uma célula a combustível autônoma” . Dissertação de Mestrado, UEM, Paraná, Brasil.

[5] TAKEISHI, K., SUZUKI, H., 2004, "Steam Reforming of Dimethyl Ether", Applied Catalysis A: General, v.260, p.111-117.

[6] BADMAEV, S., SNYTNIKOV, P. 2008, "Hydrogen production from dimethyl ether and bioethanol for fuel cell aplications", International Journal of Hydrogen Energy, v.33, p.3026-3030. 